\title{
Sistemas de alimentação e épocas de terminação sobre as medidas corporais pré-abate e da carcaça de cordeiros abatidos na região Centro-Sul do Paraná ${ }^{1}$
}

\section{Feeding systems and periods of finishing on the body and carcass measurements of lambs slaughtered in the South Central region of the Paraná ${ }^{1}$}

\author{
Odilei Rogerio Prado ${ }^{2}$; Alda Lúcia Gomes Monteiro3; Guilherme de Medeiros Bastos ${ }^{4}$; \\ Bruno Bueno Saab ${ }^{5}$; Sheila Maris do Prado Quizini'; Cesar Caldeira Pierobom ${ }^{7}$; \\ Fernando Hentz ${ }^{8}$; Thalita Manzoni Nomura ${ }^{9}$
}

\begin{abstract}
Resumo
O objetivo foi determinar o efeito do sistema de alimentação e do período do ano sobre as medidas corporais e da carcaça de cordeiros abatidos na Cooperativa Cooperaliança (Guarapuava-PR). Cordeiros Ile de France e cruzados $(\mathrm{n}=253)$ foram avaliados quando apresentavam, em média, 39,6 kg de peso corporal ao abate, e em três períodos, entre Abril e Setembro de 2010. Foram identificados 4 sistemas alimentares na terminação dos cordeiros: a) ovelhas em pastagem + cordeiros (creep-feeding; $\mathrm{n}=67$ ) ; b) ovelhas + cordeiros em pastagem e não suplementados $(n=47)$; c) ovelhas e cordeiros em pastagem e suplementados com ração concentrada $(n=30)$; d) sistema irregular de terminação $(n=109)$. Foram realizadas medidas in vivo e por ultrassonografia antes do abate e medidas na carcaça antes e após refrigeração. Cordeiros entregues para o abate entre o final do mês de agosto e a primeira quinzena do mês de setembro apresentaram resultados superiores $(p<0,05)$ quanto ao desenvolvimento muscular, rendimento de carcaça fria e espessura de gordura subcutânea na carcaça, quando comparados aos abatidos nos meses de abril e junho. Concluiu-se que o sistema de alimentação com suplementação das ovelhas e cordeiros não desmamados resultou em melhores características para as medidas corporais e na carcaça, comparado aos demais sistemas.
\end{abstract}

Palavras-chave: Compacidade, condição corporal, estado de engorduramento, ovinos, $\mathrm{pH}$

\footnotetext{
Abstract

The objective was to determine the effect of feeding system and time of the year on the in vivo and carcass characteristics of lambs slaughtered at the Cooperative Cooperaliança (Guarapuava-PR). Ile

${ }^{1}$ Projeto de Pesquisa financiado pelo CNPq.

2 Pós-Doutorando da Universidade Federal do Paraná, PPGCV/UFPR, Curitiba, PR. Bolsista CNPq. E-mail: orpradovet@gmail.com

${ }^{3}$ Laboratório de Produção e Pesquisa em Ovinos e Caprinos, UFPR, Curitiba, PR. E-mail: aldaufpr@gmail.com

${ }^{4}$ Coordenador do Laboratório de Reprodução Animal (ReproCentro), UNICENTRO, Guarapuava, PR. E-mail: gmbastos2004@, yahoo.com.br

${ }^{5}$ Médico Veterinário, Bolsista do ReproCentro, UNICENTRO, Guarapuava, PR. E-mail: bbuenosaab@hotmail.com

${ }^{6}$ Médica Veterinária, Bolsista do Laboratório de Reprodução Animal, UNICENTRO, Guarapuava, PR. E-mail: shempg@hotmail.com

${ }^{7}$ Graduando em Medicina Veterinária/Bolsista do ReproCentro, UNICENTRO, Guarapuava, PR. E-mail: cpierobom@yahoo.com.br

${ }^{8}$ Zootecnista Discente de Doutorado do PPG em Agronomia, Produção Vegetal, UFPR, Curitiba, PR. E-mail: lelopzo@gmail.com

${ }^{9}$ Zootecnista Discente de Mestrado do PPG em Ciências Veterinárias, UFPR, Curitiba, PR. E-mail: thalita-nomura@hotmail.com

* Autor para correspondência
} 
de France lambs and their crossbreds ( $\mathrm{n}=253$ ) were evaluated at slaughter with $39.6 \mathrm{~kg}$ of mean body weight in three periods between April and September 2010. Four feeding systems for finishing of lambs were identified: a) grazing dams + lambs with creep-feeding for lambs $(n=67)$; b) no supplemented, grazing dams + lambs $(\mathrm{n}=47)$; c) grazing dams + lambs, all of them supplemented with concentrate $(\mathrm{n}=30)$; $)$ irregular system of feeding $(\mathrm{n}=109)$. Measurements on lambs were carried out in vivo and by ultrasound before slaughter and the carcass measurements were taken before and after chilling. Lambs delivered for slaughter between the end of August and the first half of September showed better results $(\mathrm{p}<0.05)$ for muscle development, dressing percentage and fat thickness in the carcass compared to that slaughtered in April and June. It was concluded that the feeding system with supplementation for dams and sucking lambs resulted in better characteristics for body and carcass measurements compared to other systems.

Key words: Body condition, compactness, fatness, $\mathrm{pH}$, sheep

\section{Introdução}

A ovinocultura do Estado do Paraná tem-se mostrado promissora alternativa de diversificação das propriedades rurais e o Estado tem demonstrado forte organização do setor com a formação e consolidação de Cooperativas de produtores de carne ovina. A produção de ovinos caracterizase basicamente pela produção de carne em ciclo produtivo curto ( 9 meses), o que permite rápido retorno do capital investido, principalmente quando comparada a outras atividades pecuárias, e se realizada com bom planejamento.

Os sistemas de criação e/ou alimentação, aos quais os cordeiros são submetidos, desde o nascimento até o abate, podem afetar as características morfométricas (in vivo) e quantitativas das carcaças (RIBEIRO et al., 2009). Esses mesmos autores encontraram também resposta altamente significativa da oferta de nutrientes em sistemas com suplementação alimentar e sem o desmame dos cordeiros sobre os rendimentos de carcaça dos mesmos, levando à maior rentabilidade obtida nesses sistemas (BARROS et al., 2009).

Fernandes et al. (2010) encontraram efeito significativo dos sistemas de alimentação sobre a relação músculo:gordura de cordeiros abatidos aos 3-4 meses de idade. Além disso, notou-se efeito nas condições de acabamento e de conformação das carcaças, em função dos sistemas alimentares de terminação dos cordeiros.
Sugere-se que os mesmos efeitos possam acontecer conforme a época do ano em que os cordeiros são abatidos, pois estarão sob diferentes condições de alimentação, principalmente quando as criações são realizadas em pastagens, uma vez que as mesmas sofrem forte efeito climático sobre sua disponibilidade e, portanto, sobre a oferta de forragem aos animais. No entanto, ressaltase a importância de que a produção de cordeiros seja distribuída durante todo o ano, para que se oportunizem melhores condições de comercialização aos produtores e, assim, maior sustentabilidade da cadeia produtiva.

O objetivo deste trabalho foi verificar e quantificar os efeitos de sistema de alimentação e do período de terminação e entrega de cordeiros sobre as medidas corporais pré-abate e da carcaça de cordeiros abatidos na região Centro-Sul do Estado do Paraná.

\section{Material e Métodos}

O experimento foi conduzido no Frigorífico Keller sob inspeção estadual (SIP) em Guarapuava$\mathrm{PR}$, a partir do abate dos cordeiros entregues pelos cooperados da Cooperativa Cooperaliança de Carnes Nobres - Cordeiro Cooperaliança, em GuarapuavaPR. Previamente ao período experimental, foi aplicado questionário aos produtores cooperados para obtenção de informações pertinentes aos manejos utilizados nos rebanhos de ovinos, bem 
como, para caracterização dos sistemas alimentares utilizados na terminação dos cordeiros enviados ao abate (Tabela 1).

Foram avaliados 253 cordeiros da raça Ile de France e cruzados (média de 50,6 animais/ avaliação) com idades entre 150 a 180 dias e média de 39,6 $\mathrm{kg}$ de peso corporal ao abate, a partir das propriedades de 13 produtores cooperados. Após a aplicação do questionário e da interpretação das respostas apresentadas foram identificados 4 sistemas alimentares aplicados na cria e recria dos cordeiros: A) ovelhas em pasto + cordeiros não desmamados e suplementados em creep-feeding com ração concentrada $(n=67)$; B) ovelhas em pasto + cordeiros não desmamados e não suplementados $(n=47)$; C) ovelhas em pasto suplementadas com ração concentrada + cordeiros não desmamados e suplementados em creep-feeding com ração concentrada $(n=30)$; D) sistema irregular de terminação (sistema no qual variam freqüentemente os alimentos usados e as quantidades fornecidas aos cordeiros em fase de terminação) $(n=109)$. Para todos os sistemas, as pastagens predominantes nas propriedades foram compostas de Cynodon spp. (Tifton 85) no mês de abril, e aveia (Avena strigosa) e azevém (Lolium multiflorum L.) entre junho e setembro de 2010.

Nos sistemas em que os animais receberam suplementação concentrada, o consumo médio das ovelhas foi de $0,3 \mathrm{~kg} /$ animal/dia e para os cordeiros de $0,4 \mathrm{~kg} / \mathrm{animal} / \mathrm{dia}$, representando aproximadamente $0,5 \%$ e $1 \%$ do peso vivo para ovelhas e cordeiros, respectivamente. A ração comercial utilizada foi Agrária Ovinos ${ }^{\circledR}$, composta de radícula de malte, farelo de soja, cevada, milho integral moído, casca de soja, calcário calcítico, fosfato monobicálcico, cloreto de sódio (sal comum) mais sal mineral. A composição química da ração foi de $87,5 \% \mathrm{MS}$, $16 \%$ PB, 68\% NDT e 16\% FDA.

Foram realizadas avaliações dos animais vivos e das carcaças, entre Abril e Setembro de 2010, em três períodos distintos de abate dos cordeiros: 1) Período 1: 07 e 28 de Abril $(n=46) ; 2)$ Período 2: em 23 de Junho ( $n=87)$; 3) Período 3: entre 28 de Agosto e 15 de Setembro ( $n=120)$. 
Tabela 1. Questionário aplicado aos produtores cooperados da Cooperativa de Carnes Nobres - Cordeiro Cooperaliança - Guarapuava - PR.

\section{Cadastro de Produtores - Cooperativa Cooperaliança - Cordeiro Guarapuava}

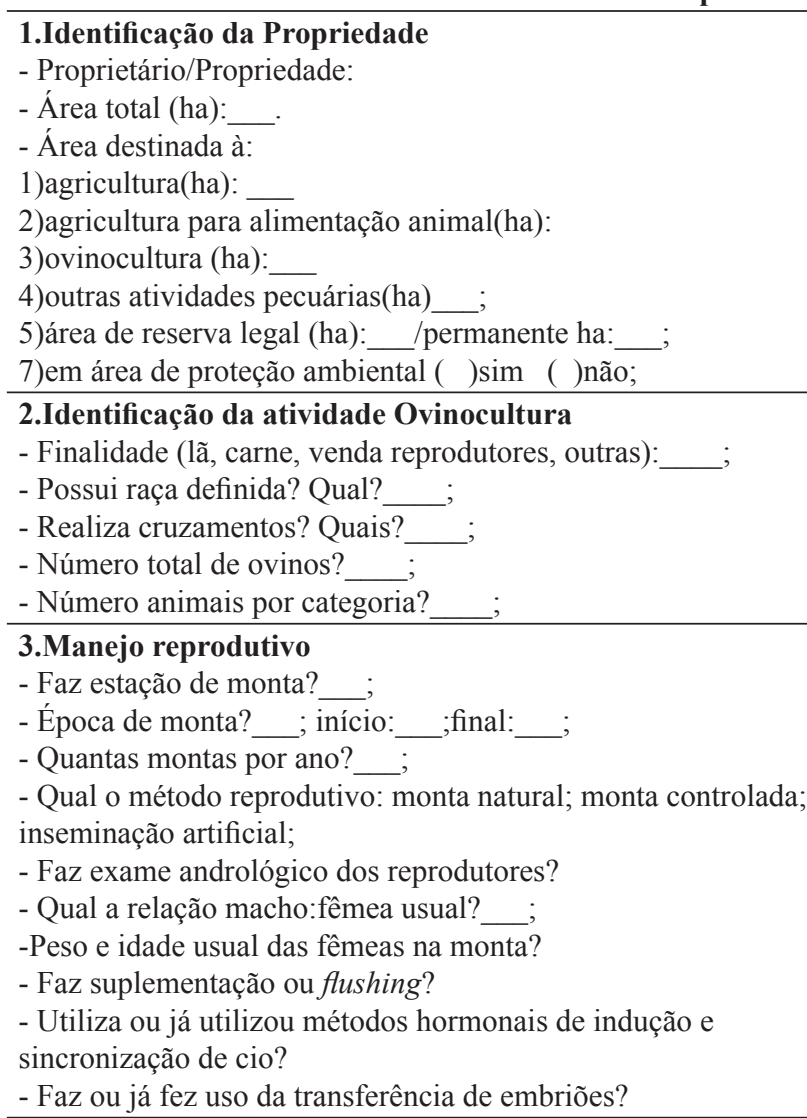

4. Índices zootécnicos no último ano

- número de fêmeas cobertas?

- número cordeiros nascidos?

- número cordeiros desmamados?

- número de ovelhas descartadas? Causa de descarte?

- número ovelhas adquiridas?

- número de reprodutores descartados?

- número de reprodutores adquiridos? Grau de sangue?

- Peso médio ao nascer dos cordeiros?

- Peso e idade média dos cordeiros ao desmame?

\section{Sistemas de Produção}

- Faz recolhimento noturno dos animais?

- Sistema de produção utilizado:

-a)ovelhas e reprodutores em pasto+ cordeiros terminados ao pé da mãe, sem o desmame e sem suplementação de nenhum tipo, em nenhuma época;

-b)ovelhas e reprodutores em pasto + cordeiros terminados ao pé da mãe, sem o desmame e com suplementação para todos; -c)ovelhas e reprodutores em pasto + cordeiros desmamados e terminados em pasto sem nenhum suplemento; -d)ovelhas e reprodutores em confinamento ou semiconfinamento; cordeiros desmamados e terminados em pasto sem nenhum tipo de suplementação;

e) ovelhas em pasto + reprodutores em confinamento ou semiconfinamento + cordeiros desmamados e terminados em pasto com algum tipo de suplementação;

f)ovelhas e reprodutores em confinamento ou semiconfinamento; cordeiros desmamados e terminados em confinamento; g) Se preferir, detalhe a seguir seu sistema de produção. - Há alguma época do ao em que o manejo difere dos citados acima?

- Utiliza algum tipo de suplemento aos cordeiros antes do desmame (creep feeding)? No pasto ou em aprisco?

- Quais os tipos de pastagens utilizadas?

- Qual a área de pastagem? Indique as espécies forrageiras por área.

- Faz uso de áreas de lavoura de verão para pasto de inverno ou vice-versa? Qual a área?

- Usa o pasto o ano todo? Se não em que época usa?

- Utiliza adubação das pastagens em alguma época? Qual a época e o adubo utilizado?

- Tem área para produção de silagem, feno, cana de açúcar, capineira ou outro alimento volumoso?

\section{Manejo Sanitário}

- Utiliza algum método de controle de verminose?

- Faz vermifugações periódicas? A cada quanto tempo? Em quais épocas do ano?

- Quantos animais recebem vermífugo? Qual o vermífugo utilizado? Faz troca de vermífugo? - Faz uso algum outro produto (homeopatia ou fitoterapia?

- Quantos animais morrem por ano comprovadamente por verminose?

- Existe alguma outra enfermidade de ocorrência no rebanho?

\section{Recursos Humanos e Infraestrutura}

- Tem funcionários na ovinocultura? Quantos? São exclusivos desta atividade?

- Qual o grau de escolaridade do funcionário?

- Recebe assistência de profissional de nível superior? Qual profissão? Quantos são?

- Qual o tipo de assistência? Permanente, eventual, regular mensal, regular quinzenal, regular semanal.

- Descreva resumidamente o tipo de infraestrutura envolvido na atividade: piquetes de pastagem, galpões, apriscos, centros de manejo, troncos, silos, depósitos de rações e fenos, laboratórios, farmácias, esterqueira, equipamentos e maquinário.

Fonte: Elaboração dos autores. 
As avaliações in vivo e nas carcaças dos cordeiros ao abate foram realizadas em 3 dias consecutivos no Frigorífico. No dia anterior ao abate (primeiro dia de avaliação), os cordeiros foram entregues às 17 horas, momento em que foi feita a pesagem em balança eletrônica para ovinos (Açores ${ }^{\circledR}$ modelo 602/SM), obtendo-se o peso vivo de fazenda (Peso Faz.) para posterior determinação do rendimento de fazenda (Rend. Faz.) aplicando-se a fórmula [(Peso Faz*0,5-1,92)*(1,045/Peso Faz)*100] descrita por Silva Sobrinho e Osório (2008). O peso obtido no momento de entrega para o abate foi considerado como peso de fazenda, uma vez que as propriedades estavam no máximo a $20 \mathrm{~km}$ de distância do Frigorífico, sendo a maioria delas desprovida de balança para pesagem de animais vivos. Após a pesagem, avaliou-se o escore de condição corporal (ECC) por um mesmo examinador, e os cordeiros eram classificados em escala de 1 (muito magro) a 5 (obeso), de acordo com o desenvolvimento de tecido muscular e de tecido adiposo sobre as apófises espinhosas e transversas das vértebras lombares, conforme metodologia descrita por Osório e Osório (2003). Na mesma data, por meio do equipamento de ultrassom ALOKA Prosound 6 com transdutor linear de 7,5 MHz, realizou-se avaliação por ultrassonografia in vivo no músculo Longissimus dorsi (L. dorsi), com previa limpeza da região a ser avaliada e posicionou-se o transdutor transversalmente à linha média dorsal, entre a $12^{\mathrm{a}} \mathrm{e}$ $13^{\text {a }}$ costelas do lado esquerdo do corpo do animal, contendo gel específico para ultrassonografia. A partir deste eram obtidas as medidas: profundidade do músculo L. dorsi (PLD), comprimento do músculo L. dorsi (CLD), espessura de gordura sobre o L. dorsi (EGLD). Para determinar a área de olho de lombo (AOL) do músculo L. dorsi foi aplicada a fórmula [(CLD/2) x $(\mathrm{PLD} / 2) \times 3,1416]$, descrita por Cezar e Sousa (2007).

Na manhã seguinte (segundo dia de avalição), os cordeiros foram abatidos segundo as normas estabelecidaspeloServiçodeInspeçãodoParaná(SIP/ POA). Após o abate, as carcaças foram penduradas em ganchos pelas articulações tarsometatarsianas (distanciadas em $17 \mathrm{~cm}$ ) e procederam-se as avaliações nas carcaças quentes, iniciando-se com aferição do potencial hidrogeniônico ( $\mathrm{pH}$ ), com auxílio de um potenciômetro portátil digital (Hanna Instruments $\left.{ }^{\circledR}\right)$ modelo HI 99163 com faca para carnes e eletrodo FC 232D no músculo L. dorsi entre a $12^{\mathrm{a}}$ e $13^{\mathrm{a}}$ costelas do lado esquerdo das carcaças. Então, as mesmas foram submetidas à refrigeração em câmara frigorífica a $4^{\circ} \mathrm{C}$ por 24 horas.

No terceiro dia de avaliação, após o período de refrigeração das carcaças, novamente mensurouse o $\mathrm{pH}$ ( $\mathrm{pH} 24 \mathrm{~h})$ e as mesmas foram pesadas em balança eletrônica Toledo® $30 \mathrm{~kg}$, para obtenção do peso de carcaça fria (PCF) e posterior determinação do rendimento de carcaça fria (RCF) ou rendimento comercial, pelo cálculo da relação entre o peso de carcaça fria e o peso vivo ao abate (PCF/PVA $\mathrm{x}$ 100). Para mensurar a espessura de gordura subcutânea (EGS) sobre o músculo L. dorsi, procedeu-se o corte transversal do referido músculo com faca, entre a $12^{\mathrm{a}}$ e $13^{\mathrm{a}}$ costelas do lado esquerdo da carcaça e a medida foi tomada com paquímetro digital Mitutoyo ${ }^{\circledR} \bmod .300 \mathrm{~mm}$.

As avaliações subjetivas das carcaças (conformação, coloração e estado de engorduramento) foram feitas visualmente, seguindo metodologia descrita por Osório e Osório (2003). Para avaliação da conformação (CONF), considerou-se a espessura dos planos musculares e adiposos em relação ao tamanho do esqueleto e as carcaças foram classificadas de 1 (muito pobre), 2 (aceitável), 3 (boa), 4 (superior) a 5 (excelente). Em seguida, foi realizada a avaliação da coloração (COR) no músculo Rectus abdominis, utilizando escala de 1 (rosa claro), 2 (rosa), 3 (vermelho claro), 4 (vermelho) a 5 (vermelho escuro). A quantidade e a distribuição da gordura nas carcaças, denominada estado de engorduramento (EE), foi avaliada atribuindo-se notas em escala de 1 (excessivamente magra) a 5 (excessivamente gorda). A medida de compacidade das carcaças (COMP) foi determinada pela relação entre o peso de carcaça fria $(\mathrm{PCF})$ e o 
comprimento interno da carcaça (medido com fita métrica, desde o bordo anterior do osso púbis até o bordo cranial da primeira costela $-\mathrm{kg} / \mathrm{cm}$ ).

Os dados foram submetidos à análise de variância para dados desbalanceados, devido ao número de repetições diferentes entre as épocas do ano e sistemas de produção. Como nenhuma das variáveis satisfez o pressuposto de normalidade para análise de variância, os dados foram analisados pelo teste não paramétrico de Kruskal-Wallis para amostras independentes. As variáveis EGLD e EGS foram transformadas pelo método Box-Cox por não apresentarem distribuição normal, e as médias foram comparadas pelo teste de Tukey a 5\%. A análise estatística utilizou o software R versão 2.10.1 (R. SOFTWARE FOR STATISTICAL ANALYSIS, 2009).

\section{Resultados e Discussão}

O questionário aplicado aos produtores da Cooperativa Cooperaliança demonstrou que mais de um terço $(43,1 \%)$ das propriedades não apresentavam sistema de alimentação bem definido e constante, durante a terminação dos cordeiros nos períodos pesquisados. A falta de planejamento alimentar prévio para esta importante fase, além de deixar o produtor vulnerável à instabilidade de preços dos alimentos praticados pelo comércio, prejudica o desempenho dos cordeiros com mudanças no manejo alimentar, obtendo como conseqüência os piores resultados nas avaliações in vivo e na carcaça dos cordeiros abatidos (Tabela 1). Assim, além de prejudicar o resultado econômico da sua atividade, pois alguns parâmetros avaliados são utilizados para pagamento do produto final, a dificuldade no estabelecimento de um plano alimentar acaba por comprometer a cadeia produtiva, a começar pelo compromisso de produção que a Cooperativa deve cumprir para atender a seus clientes, a regularidade na entrega do produto, além da uniformidade da qualidade do produto entregue durante o ano.
Cooperativa Cooperaliança continham escore corporal ao redor de 3 (Tabela 2), com ínfima amplitude entre os valores desta característica $(2,95$ a 3,01), considerando todos os períodos de entrega e os sistemas de produção empregados. Embora tenham apresentado tal homogeneidade, algumas outras variáveis corporais e das carcaças sofreram efeito $(\mathrm{P}<0,05)$ da época em que foram abatidos e também do sistema de alimentação ao qual foram submetidos os animais.

Houve efeito $(\mathrm{P}<0,05)$ da época de terminação dos cordeiros e dos sistemas de alimentação sobre as medidas corporais tomadas por ultrassonografia, tais como a área e a profundidade da secção do músculo L. dorsi, tomadas entre a $12^{\mathrm{a}}$ e a $13^{\mathrm{a}}$ costelas. Os cordeiros terminados e abatidos no período 3 ( 28 de agosto e 15 de setembro) apresentaram o músculo $L$. dorsi com maiores profundidades e área, indicando maior desenvolvimento muscular desses animais, quando comparados com os cordeiros entregues no período 1 (Abril) e no período 2 (Junho), que passaram por terminação em pastagens de verão e de outono, respectivamente.

Essa mesma resposta foi observada com a compacidade e a conformação das carcaças, que também são variáveis indicativas de planos musculares bem desenvolvidos (TONETTO et al., 2004). Esse melhor desenvolvimento muscular refletiu em maiores $(\mathrm{P}<0,05)$ rendimentos das carcaças resfriadas, efeito este que também é devido ao grupo racial ao qual pertenciam os cordeiros. A melhor oferta alimentar nos meses de agosto e setembro/2010, associada a animais de raça especializada na produção de carne potencializaram os resultados de rendimento e musculosidade nas carcaças. Como o pagamento das carcaças aos produtores se dá em função do peso e rendimento, estes poderão ter melhores remunerações para animais entregues no período 3 (agosto e setembro), quando comparadas aos dos outros períodos avaliados.

Os cordeiros entregues para abate na 


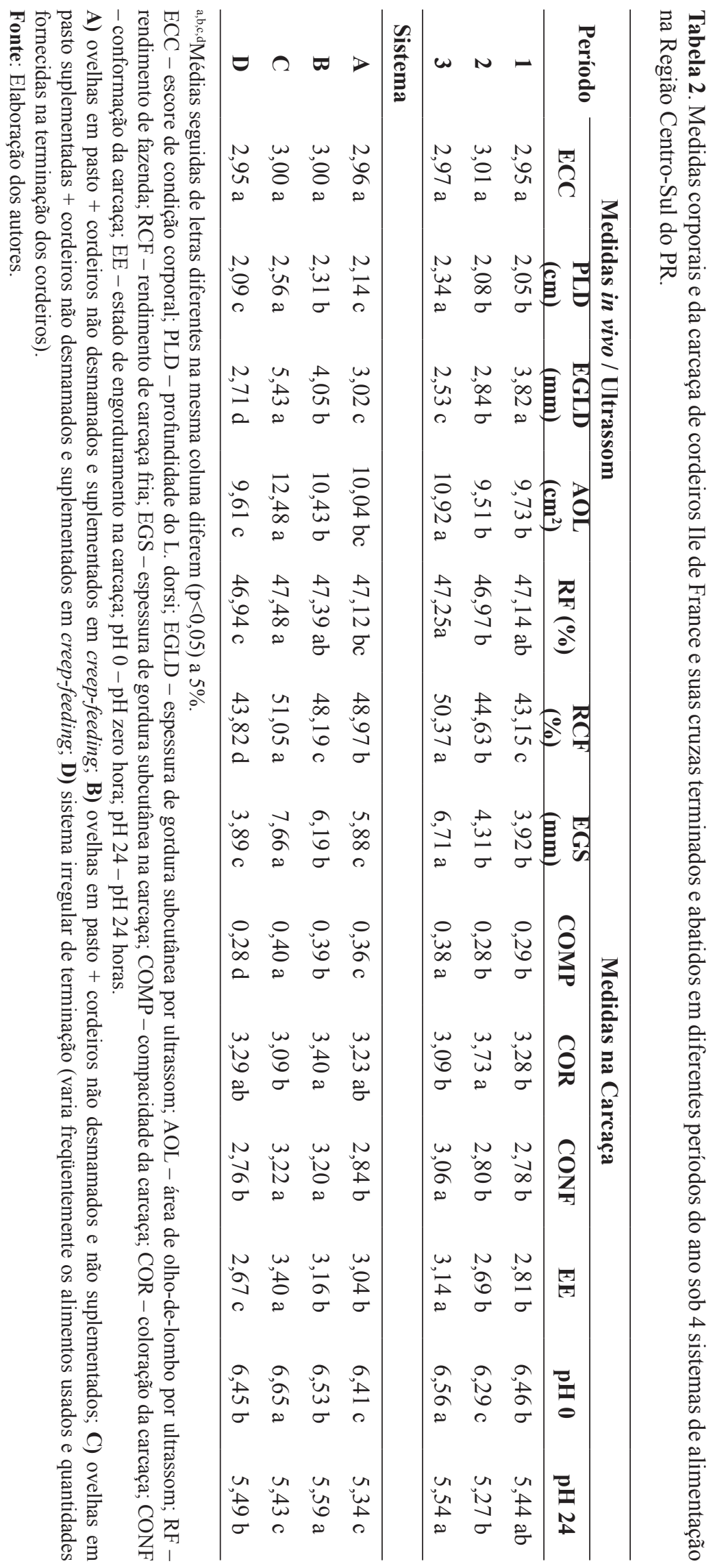


Quando se analisam os dados de composição em gordura das carcaças, nota-se a mesma resposta, ou seja, os cordeiros abatidos no período 3 foram os que apresentaram maior $(\mathrm{P}<0,05)$ espessura de gordura $(\mathrm{mm})$ e maior pontuação na avaliação visual do estado de engorduramento das carcaças. Quanto ao grau de engorduramento, para o qual seguiu-se escala de 1 a 5 , as carcaças poderiam ser classificadas como de gordura média, conforme o Regulamento (CE) n. 22/2008 (2008), que estabelece a aplicação do modelo comunitário europeu de classificação de carcaças ovinas maiores que $13 \mathrm{~kg}$. Os valores objetivos de gordura subcutânea variaram entre 3,92 a $6,71 \mathrm{~mm}$, o que pode ser considerada elevada cobertura comparando-se aos resultados de carcaças de cordeiros normalmente abatidos no Brasil, especialmente para os cordeiros abatidos entre agosto e setembro. Fernandes et al. (2009) avaliando a espessura de gordura das carcaças de cordeiros Suffolk desmamados e abatidos aos $32 \mathrm{~kg}$ de peso vivo e recebendo níveis crescentes de suplementação concentrada $(0,1,2 \% \mathrm{PV}$ e $a d$ libitum), encontraram valores de espessura de gordura de $1,18 \mathrm{~mm}, 1,36 \mathrm{~mm}, 1,92 \mathrm{~mm}$ e $1,92 \mathrm{~mm}$, respectivamente. Fernandes et al. (2010) avaliando carcaças de cordeiros abatidos aos $32 \mathrm{~kg}$ peso vivo e terminados sem desmame, com suplementação concentrada em 1\% PV e sem suplementação em pastagem de azevém, não encontraram diferença $(p>0,05)$ para espessura de gordura das carcaças do primeiro $(2,60 \mathrm{~mm})$ e segundo $(1,93 \mathrm{~mm})$ sistema, respectivamente. Os maiores valores de espessura de gordura das carcaças encontrados no presente trabalho, quando comparado com a literatura citada pode ser devido ao maior peso vivo dos cordeiros ao abate, média de 39,6 kg. Para cordeiros que são abatidos aos $32 \mathrm{~kg}$ de peso vivo, Siqueira e Fernandes (2000), descreveram que as carcaças devem ter no mínimo 1,4 mm de espessura de gordura.

O sistema de criação em pasto com suplementação das ovelhas e dos cordeiros em creep feeding superou $(\mathrm{P}<0,05)$ os outros sistemas alimentares para as características avaliadas por ultrassonografia, apresentando maiores valores para profundidade do músculo L.dorsi, (PLD), espessura de gordura sobre o L. dorsi (EGLD) e área de olho de lombo (AOL).

A espessura de gordura avaliada no ultrassom apresentou correlação positiva $(0,515)$ e significativa $(\mathrm{P}<0,05)$ com a mesma variável medida nas carcaças. A mensuração da espessura de gordura subcutânea e da área e profundidade da secção do músculo L. dorsi constituem as principais características avaliadas por ultrassom nos animais pré-abate. Conforme Cartaxo e Sousa (2008) são poucos os trabalhos com relatos de correlação significativa em pequenos ruminantes para estas variáveis, in vivo e na carcaça. Como a maioria das pesquisas é feita com animais muito jovens, que apresentam pequena espessura de gordura subcutânea no momento do abate, dificuldades na mensuração das imagens são previsíveis.

Quanto aos valores de $\mathrm{pH}$ medidos no tempo zero e 24 horas após o abate, embora tenha havido diferença significativa $(\mathrm{P}<0,05)$ entre os sistemas alimentares, os valores nos dois momentos estiveram todos dentro da amplitude esperada para a espécie ovina. A queda do $\mathrm{pH}$ nas 24 horas ocorreu com a mesma intensidade (1,02 em 24 horas). Osório et al. (2009) afirmaram que o aumento do nível nutricional pode estar associado a $\mathrm{pHs}$ mais altos nas carcaças resfriadas 24 horas após abate.

Isso pode ter ocorrido com os animais abatidos entre Agosto e Setembro, que nessa Região do Brasil, têm a oportunidade de pastejo de espécies forrageiras hibernais, tais como aveia (Avena strigosa) e azevém (Lolium multiflorum L.), que normalmente são disponibilizadas para pastejo desde Junho (no caso da aveia, de plantio mais precoce) até Outubro (no caso do azevém, de produção hiberno-primaveril). Essas pastagens, nessa região do Paraná, normalmente apresentam valores de proteína bruta entre 18 a $22 \%$, e com elevada digestibilidade $(>75 \%)$, além de elevada relação folha:colmo, conforme descrevem Pellegrini et al. 
(2010), o que pode ser considerada uma importante fonte de nutrientes aos animais. De qualquer forma, a queda nos valores de $\mathrm{pH}$ para níveis entre 5,4 a 5,7 às 24 horas pós-mortem indicam claramente que foi possível obter carcaças de qualidade quanto à esse aspecto, conforme Olleta e Sañudo (2009).

Quanto à cor da carne aspecto visual de grande importância ao consumidor por estar relacionado à percepção de frescor e boa qualidade obteve-se cor ao redor de vermelho claro, segundo a classificação visual adaptada de Colomer-Rocher (1988). Os cordeiros abatidos no período 2 (Junho - Tabela 1) apresentam carne de cor vermelha clara pouco mais intensa $(\mathrm{P}<0,05)$; todavia, os demais cordeiros avaliados tiveram cor muito próxima deste valor. A aceitação da cor depende de vários fatores, entre eles, hábitos de consumo regionais e costumes (PINHEIRO et al., 2010). Também a intensidade da cor vermelha pode variar conforme aumenta a idade e o peso ao abate e conforme varia a alimentação dos animais (OLLETA; SAÑUDO, 2009).

Quanto aos sistemas de produção, os mesmos afetaram principalmente e de forma bastante coerente, as características relacionadas ao desenvolvimento muscular dos cordeiros (Tabela 1): área e profundidade da secção do músculo L. dorsi, medida nos cordeiros pré-abate com ultrassom, e mais a compacidade e a conformação das carcaças. Nesse caso, os cordeiros provenientes de sistemas em que os produtores não aplicavam um sistema padronizado de terminação dos cordeiros, resultaram em animais com piores valores quanto à profundidade e área de lombo $(2,09 \mathrm{~cm} ; 9,61$ $\left.\mathrm{cm}^{2}\right)$, compacidade $(0,28)$ e conformação $(2,76)$ das carcaças, indicando pior desenvolvimento muscular. O mesmo ocorreu para o rendimento das carcaças frias, cujos valores médios estiveram em 43,82\%, comparado aos 3 outros sistemas que resultaram em cordeiros com carcaças de rendimento entre 48 e 51\%. Esse aspecto deve ser salientado, pois o pagamento aos produtores cooperados da Cooperativa Cooperaliança é feito em função de duas classificações nas carcaças: cordeiro mamão (entre 14 e $20 \mathrm{~kg}$ ) e cordeiro precoce (entre 20,1 e 25 $\mathrm{kg}$ ). Assim, quanto maiores os pesos e rendimentos nas carcaças, a menores idades, melhores também serão as receitas do produtor com a venda de cordeiros, elevando o resultado econômico da atividade, aumentando a participação na receita total da propriedade rural e, dessa forma, deixando de ser uma atividade marginal que gera valores inexpressivos de receita.

Barros et al. (2009) observaram que os fatores determinantes da rentabilidade na produção de cordeiros para carne em diferentes sistemas de produção no Paraná foram o número de cordeiros entregues para abate e o peso e rendimento das carcaças.

Analisando as respostas dos produtores ao questionário aplicado (Quadro 1), pode-se dizer que esse sistema denominado como irregular consistia, em sua maioria, de rebanhos ovinos que permanecem durante todo o ano em pastagem nativa com baixa oferta de forragem, com suplementação eventual; nesse caso, a oferta de suplemento não foi feita de acordo com as exigências dos animais, estabelecidos pelo NRC (2007), além de ser ocasional e inconstante. Este produto era formado por resíduos de culturas de grãos disponíveis na propriedade, fornecido em quantidades pequenas e variáveis, não considerando as diferentes exigências nutricionais entre as categorias do rebanho. A impossibilidade de caracterizar o próprio sistema de criação e terminação dos cordeiros, a partir do preenchimento do questionário, indica eventual falta de planejamento alimentar para o rebanho, por parte dos produtores. Segundo levantamento feito por Monteiro et al. (2011), 84,6\% de técnicos ligados à ovinocultura na Região Sul do Brasil afirmaram ser a melhoria e o planejamento de sistemas alimentares de ovelhas e cordeiros a principal estratégia para o incremento da produção de ovinos nesta Região.

Os melhores valores de rendimento de carcaça (Tabela 1), desenvolvimento muscular e cobertura de gordura, quando os resultados são interpretados 
em seu conjunto, correspondem aos cordeiros provenientes do sistema no qual os animais eram suplementados com concentrado, tanto as ovelhas quanto os cordeiros. O mesmo ocorre para gordura subcutânea, tanto na medida in vivo por ultrassom, que variou entre 2,71 (sistema irregular) a $5,43 \mathrm{~cm}$ (ovelhas suplementadas em pastagem + cordeiros suplementados em creep feeding), quanto à gordura medida diretamente na carcaça $(3,89$ a $7,66 \mathrm{~cm}$, respectivamente).

Considerando que o rendimento das carcaças é a característica que determina a remuneração dos produtores, devemos analisar essa característica em especial. Nesse caso, o maior rendimento médio (51\%) foi obtido a partir dos cordeiros que recebiam suplementação e suas mães também. Em seguida, os rendimentos mais favoráveis foram observados nos cordeiros suplementados em creep feeding $(48,9 \%)$ e dos cordeiros que eram terminados ao pé da mãe em pasto cultivado, sem suplementação $(48,1 \%)$. Todos esses valores de rendimento podem dar resultados satisfatórios do ponto de vista de remuneração, e são considerados valores bastante interessantes para cordeiros entre 5-6 meses de idade.

Conclui-se que o sistema de alimentação com suplementação das ovelhas e cordeiros não desmamados resultou em melhores características para as medidas corporais e na carcaça, comparado aos demais sistemas. Nota-se que a falta de planejamento alimentar e a eventualidade no atendimento de possíveis exigências nutricionais do rebanho ovino nas propriedades, especialmente no período de cria e terminação dos cordeiros, comprometem os parâmetros avaliados in vivo e na carcaça dos cordeiros destinados a produção de carne.

Embora os resultados claramente indiquem que, para a Região Centro Sul do Paraná, a terminação no período de inverno e a entrega para o abate na primavera é a melhor opção, considerando o rendimento e a qualidade do produto final comercializável, essa proposição vai contra a busca da melhor distribuição e regularidade na oferta de cordeiros ao mercado consumidor durante o ano. Sendo assim, o que se deve recomendar é que se planeje e se busque a adequada oferta de alimento em todos os períodos do ano, para que se possa alcançar esse resultado favorável, independente de época do ano.

\section{Agradecimentos}

Ao Conselho Nacional de Desenvolvimento Científico e Tecnológico - CNPq, pelo suporte financeiro (Projeto 574674/2008-0). A Cooperativa Cooperaliança de Guarapuava-PR, técnicos e cooperados, pela colaboração na execução do trabalho. Ao SENAR/PR pelo custeio de deslocamento e estadia ao local do experimento.

\section{Referências}

BARROS, C. S.; MONTEIRO, A. L. G.; POLI, C. H. E. C.; DITTRICH, J. R.; CANZIANI, J. R. F.; FERNANDES, M. A. M. Rentabilidade da produção de ovinos de corte em pastagem e confinamento. Revista Brasileira de Zootecnia, Viçosa, v. 38, n. 11, p. 22702279, 2009.

CARTAXO, F. Q.; SOUSA, W. H. de. Correlações entre as características obtidas in vivo por ultra-som e as obtidas na carcaça de cordeiros terminados em confinamento. Revista Brasileira de Zootecnia, Viçosa, v. 37, n. 8, p. 1490-1495, 2008.

CEZAR, M. F.; SOUSA, W. H. Carcaças ovinas e caprinas: obtenção, avaliação e classificação. Uberaba, MG: Agropecuária Tropical, 2007. 147 p.

COLOMER-ROCHER, F. Estúdio de los parâmetros que definem los caracteres cuantitativos y cualitativos de las canales. In: CURSO INTERNACIONAL SOBRE PRODUCCIÓN DE CARNE Y LECHE CON BASES EM PASTOS Y FORRAGES, 1988, La Coruña. Proceedings... La Coruña, España, 1988. p. 108.

FERNANDES, M. A. M.; MONTEIRO, A. L. G.; POLI, C. H. E. C.; BARROS, C. S. de; PRADO, O. R.; SALGADO, J. A. Composição tecidual e perfil de ácidos graxos do lombo de cordeiros terminados em pasto com níveis de suplementação concentrada. Ciência Rural, Santa Maria, v. 39, n. 8, p. 2485-2490, 2009. 
FERNANDES, M. A. M.; MONTEIRO, A. L. G.; POLI, C. H. E. C.; BARROS, C. S. de; ALMEIDA, R. de; RIBEIRO, T. M. D. Composição tecidual da carcaça e perfil de ácidos graxos da carne de cordeiros terminados a pasto ou em confinamento. Revista Brasileira de Zootecnia, Viçosa, v. 39, n. 7, p. 1600-1609, 2010.

MONTEIRO, A. L. G.; POLI, C. H. E. C.; PRADO, O. R.; SILVA, C. J. A. da; OLIVEIRA, L. de; SEQUINEL, F. C.; HENTZ, F. Estratégias para incrementar a produção de cordeiros no Sul do Brasil. In: SIMPÓSIO INTERNACIONAL DE CAPRINOS E OVINOS DE CORTE, 5., 2011, João Pessoa. Anais... João Pessoa: EMEPA, 2011. CD-ROM.

NATIONAL RESEARCH COUNCIL - NRC. Nutrient requirements of small ruminants: sheep, goats, cervids and new world camelids. Washington: National Academy Press, 2007. 362 p.

OLLETA, J. L.; SAÑUDO, C. La carne ovina. In: ASTIZ, C. S.; BRIZ, R. C. (Ed.). Ovinotecnia: producción y economia en la especie ovina. Zaragoza: Prensas Universitaria de Zaragoza, 2009. 494 p.

OSÓRIO, J. C. da S.; OSÓRIO, M. T. M.; OLIVEIRA, N. R. M. de; ESTEVES, R. M. G.; JARDIM, R. D. Estudo da variação do $\mathrm{pH}$ da carne em cordeiros Corriedale e Ideal criados em três sistemas alimentares. PUBVET, Londrina, v. 3, n. 10, ed. 71, art. 297, 2009.

OSÓRIO, J. C. S.; OSÓRIO, M. T. M. Produção de carne ovina: técnica de avaliação in vivo e na carcaça. Pelotas: Universidade Federal de Pelotas, 2003. 73 p.

PELLEGRINI, L. G. de; MONTEIRO, A. L. G.; NEUMANN, M.; MORAES, A. de; BONA FILHO, A.; MOLENTO, M. B.; PELEGRIN, A. C. R. S. de. Produção de cordeiros em pastejo contínuo de azevém anual submetido a adubação nitrogenada. Ciência Rural, Santa Maria, v. 40, n. 6, p. 1399-1404, 2010.
PINHEIRO, R. B.; JORGE, A. M.; SOUZA, H. B. A.; BOIAGO, M. M. Coloração da gordura e qualidade da carne de ovelhas de descarte abatidas em distintos estágios fisiológicos. Arquivo Brasileiro de Medicina Veterinária e Zootecnia, Belo Horizonte, v. 62, n. 2, p. 468-474, 2010.

R. Software for Statistical Analysis. R version 2.10.1. The R Foundation For Statistical Computing, Viena, 2009.

REGULAMENTO (CE) n. 22/2008 de la Comisión Europea, 11 de Enero de 2008, Disposiciones de Aplicación del Modelo Comunitario Europeu de Clasificación de Canales de Ovino. Madrid, 2008.

RIBEIRO, T. M. D.; MONTEIRO, A. L. G.; PRADO, O. R.; NATEL, A. S.; SALGADO, J. A.; PIAZZETTA, H. V. L.; FERNANDES, S. R. Desempenho animal e características das carcaças de cordeiros em quatro sistemas de produção. Revista Brasileira de Saúde e Produção Animal, Salvador, v. 10, n. 2, p. 366-378, 2009.

SILVA SOBRINHO, A. G. da; OSÓRIO, J. C. da S. Aspectos quantitativos da produção de carne ovina. In: SILVA SOBRINHO, A. G. da; SAÑUDO, C.; OSÓRIO, J. C. da S.; ARRIBAS, M. del M. C.; OSÓRIO, M. T. M. Produção de carne ovina. Jaboticabal: Funep, 2008. p. 1-68.

SIQUEIRA, E. R.; FERNANDES, S. Efeito do genótipo sobre as medidas objetivas e subjetivas da carcaça de cordeiros terminados em confinamento. Revista Brasileira de Zootecnia, Viçosa, v. 29, n. 1, p. 306-311, 2000.

TONETTO, C. J.; PIRES, C. C.; MÜLLER, L.; DA ROCHA, M. G.; DA SILVA, J. H. S.; CARDOSO, A. R.; PERES NETO, D. Ganho de peso e características da carcaça de cordeiros terminados em pastagem natural suplementada, pastagem cultivada de Azevém (Lolium multiflorum Lam.) e confinamento. Revista Brasileira de Zootecnia, Viçosa, v. 33, n. 1, p. 225-233, 2004. 
